\title{
A INSTITUCIONALIZAÇÃO DA EDUCAÇÃO FÍSICA NA IMPRENSA: A CONSTRUÇÃO DA ESCOLA SUPERIOR DE EDUCAÇÃO PHYSICA DE S. PAULO NA DÉCADA DE 1930
}

\author{
THE INSTITUTIONALIZATION OF PHYSICAL EDUCATION IN PRESS: BUILDING \\ THE "ESCOLA SUPERIOR DE EDUCAÇÃO PHYSICA DE S. PAULO" IN THE \\ 1930s.
}

\section{LA INSTITUCIONALIZACIÓN DE LA EDUCACIÓN FÍSICA EN LA PRENSA: LA CONSTRUCCIÓN DE LA "ESCOLA SUPERIOR DE EDUCAÇÃO PHYSICA DE S. PAULO" EN LA DÉCADA DE 1930.}

\section{Edivaldo Góis Junior*}

\section{Palavras chave:}

História.

Educação Física.

Imprensa.

Modernidade.

São Paulo.

Keywords:

History.

Physical Education.

Press.

Modernity.

São Paulo.

Palabras clave:

Historia.

Educación Física.

Prensa.

Modernidad.

São Paulo.
Resumo: 0 objetivo desta pesquisa é investigar a recepção da imprensa em relação à institucionalização da Educação Física, exemplificada pela criação da "Escola Superior de Educação Physica". O corpo documental foi construído a partir da imprensa, principalmente, pelo diário Correio Paulistano, possibilitando a formulação de uma narrativa sobre as práticas corporais presentes nos discursos jornalísticos na década de 1930, revelando adesões à modernidade e silêncios em relação a determinadas tradições.

Abstract: This research investigates São Paulo's press's reaction to the institutionalization of Physical Education, exemplified by the establishment of the "Escola Superior de Educação Physica". The documents were collected from newspapers, mainly Correio Paulistano - a daily newspaper from that city. Thus, we describe a narrative about bodily practices present in journalistic discourses in the 1930s, revealing accessions to modernity and silences on certain traditions.

Resumen: El objetivo de este estudio es investigar la presencia en la prensa de São Paulo de materias sobre la institucionalización de la Educación Física, ejemplificada por la creación de la "Escola Superior de Educação Physica". El cuerpo documental fue construido a partir de la prensa, especialmente el periódico "Correio Paulistano', lo que permite la formulación de una narrativa sobre las prácticas corporales presentes en los discursos periodísticos en la década de 1930, revelando adhesiones a la modernidad y silencios acerca de determinadas tradiciones.
*Universidade Estadual de Campinas. (UNICAMP). Campinas, SP, Brasil. E-mail: egoisjunior@gmail.com

Recebido em: 02-11-2016 Aprovado em: 03-05-2017

(c) (1) (8) Licence 


\section{INTRODUÇÃO}

A educação física brasileira, não obstante um movimento também internacional, teve médicos, educadores e militares como apoiadores em seu projeto de institucionalização marcado por sua presença nas escolas e em cursos de formação especializados.

A historiografia dedicada à educação física na escola produziu vários estudos que relacionaram sua institucionalização no currículo com objetivos militares, nacionalistas e também a projetos modernos de sociedade. Corpos higienizados pela crença em pedagogias sustentadas pelo discurso científico como progenitor de caminhos seguros de civilidade e progresso social. Como exemplos, na Escócia, Macrae (2012) demonstrou a importância que o governo e importantes educadores deram à educação física na reforma curricular de 1931. Na Turquia, Cüneyd Okay (2003) vislumbrou a valorização das festas esportivas com jovens e crianças com o objetivo de estimular um sentimento de nacionalismo nas primeiras décadas do século XX. Na Suécia, Suzanne Lundvall (2015) evidenciou que a ginástica sueca desenvolvida por Per-Henrik Ling no século XIX, exportada para diversos países no mundo, tinha objetivos fortemente ligados à saúde, mas também ao militarismo. Na Argentina, Pablo Scharagrodsky (2014) afirmou que na década de 1920, diante de conflitos sobre a questão do melhor método de educação física, os argentinos optaram por uma organização didática nacional com forte influência médica, permitindo e proibindo tipos específicos de movimento. Na Alemanha, Michael Krüger (1996) narrou o papel da ginástica e suas associações civis na construção da identidade nacional desde o século XIX. Na França, Georges Vigarello (2003) descreveu uma ginástica mecânica, calculada, bastante objetiva que tinha como lema o controle corporal em uma lenta difusão no século XIX. Na Inglaterra, para John Welshman (1998), mesmo sob a influência dos esportes, a ginástica higiênica tinha também seus defensores.

Ao observar essas interpretações ao redor do mundo, percebemos que discursos modernos proferidos por médicos e militares, quando traduzidos em práticas, mais especificamente, em uma educação física delimitada por ginásticas europeias e também pelos esportes e jogos infantis, deram certa homogeneidade à institucionalização de uma pedagogia especializada pautada pela modernidade. Desse modo, a historiografia internacional da área a partir de interpretações diversas vislumbrou o papel destacado de médicos, educadores e militares como personagens relevantes na construção da Educação Física com letras maiúsculas, ou seja, sistematizando práticas e conhecimentos no sentido de forjar uma ocupação especializada presente nas escolas, como também fora delas em associações e clubes esportivos. Os narradores enfatizam os ideários médico e militar presentes desde 0 século XIX no ensino de práticas corporais (SILVA, 2014), como as ginásticas e os esportes.

Neste estudo, demarcado pela cidade de São Paulo, temos como objetivo dar centralidade à educação física oriunda de discursos marcados pela modernidade mediante sua presença em jornais na década de 1930. De forma mais específica, almejamos analisar a recepção da imprensa paulistana em relação à institucionalização da Educação Física, exemplificada pela criação da "Escola Superior de Educação Physica" que seria o embrião de uma das principais faculdades da área no país, a Escola de Educação Física e Esportes da Universidade de São Paulo. Enfim, qual seria a educação física evidenciada pelos jornais na constituição de uma escola paulista, responsável pela formação de professores civis na área? 
Para isso, em termos metodológicos, foram consultados o acervo do Arquivo Público de São Paulo e o acervo digital da Biblioteca Nacional. As fontes foram os jornais, que para Campos (2012) produzem pistas verossímeis sobre o passado, pois se aproximam da cultura de um tempo, revelando representações que vão além de seus escritores, que atingem, também, seus leitores, na constituição de uma prática cultural onde se imbricam gostos, desejos e visões de mundo, em outras palavras, estabelece-se um contrato de confiança entre seus escritos e suas leituras (CAMPOS, 2012). Precisamos, então, em seu manuseio estar atentos à crítica das fontes, refletindo sobre as intenções de seus produtores, os espaços nos quais circulavam e as representações que emanavam de seus discursos.

Em particular, nesta pesquisa, destacamos como fonte o jornal Correio Paulistano, um dos maiores do país, sendo um dos primeiros diários da cidade de São Paulo. Criado pelo tipógrafo Joaquim Roberto de Azevedo Marques em 1854, circulou na cidade até 1963, publicando 33.882 edições em mais de cem anos de existência. Segundo Ângela Thalassa (2007), em um período inicial, ele não tinha vinculação com um partido político, embora seu redator, Pedro Taques de Almeida Alvim, fosse membro do Partido Conservador. Entretanto, a partir do último quartil do século XIX, o jornal passa a ser fortemente influenciado pelo Partido Republicano Paulista, representando princípios liberais, filtrados pelo conservadorismo das oligarquias rurais do café. Durante a década de 1920, o diário apoiou o movimento modernista, dando ampla cobertura à Semana de Arte Moderna de 1922; e também se destacou pela crítica à Revolução de 1930 (THALASSA, 2007). O diário defendia uma liderança paulista no campo político, criando modelos de desenvolvimento que deveriam ser exemplos para o restante do país. Neste sentido, como porta-voz de uma visão política liberal, foi preservado como parte de uma grande imprensa representante de uma identidade paulista, autoproclamava-se como "anfitrião da história bandeirante" (THALASSA, 2007, p. 42). Por isso, essa fonte foi importante para a análise de um projeto moderno, parcialmente representado pela institucionalização de um novo órgão público estadual dedicado à formação de professores de educação física em São Paulo. Na constituição do corpo documental, foram encontradas 55 reportagens que versavam sobre educação física no Correio Paulistano. A partir deste conjunto, nove documentos foram selecionados e analisados por noticiarem, primordialmente, eventos relacionados à "Escola Superior de Educação Physica" de São Paulo na década de 1930. Além disso, quatro documentos de outras publicações foram analisados, pois constituíam evidências relevantes para a interpretação e construção da narrativa.

\section{DOS DISCURSOS JORNALÍSTICOS E DA DEFESA DA EDUCAÇÃO FÍSICA}

No Brasil, no início do século XX, a sociedade, principalmente a partir dos discursos dos intelectuais, reclamava através da educação e saúde a modernização do país. Não se tratava de um projeto político e intelectual original, as principais cidades europeias passaram por mudanças semelhantes já no século XIX, conforme nos descreve o sociólogo Richard Sennett (1997), quando a construção de uma civilidade urbana, higiênica, racional, conforme as prescrições dos médicos e intelectuais, esboçava-se na arquitetura, no corpo e no planejamento urbano. No Brasil, tanto em São Paulo quanto no Rio de Janeiro, os discursos e práticas seguiam as prerrogativas da higiene pública no início do século XX (SEVCENKO, 1992; CHALHOUB, 2012), portanto, não destoam dos projetos de cidades europeias como Londres e Paris. Essa representação de sociedade moderna encontrava seus adeptos no país, com 
grandes conglomerados populacionais que almejavam reproduzir cenários urbanos europeus. Para Sevcenko (1998) esse período assinala no país a introdução de novos hábitos de consumo, desenvolvendo um mercado publicitário, de periódicos, práticas esportivas, música, dança e cinema. Anunciados em nome do "novo", práticas modernas levavam aos prazeres individuais, ao conforto, aos divertimentos, que nas grandes cidades brasileiras estavam mais restritos a determinadas parcelas da população. Além disso, em um cenário de contrastes e luta pela sobrevivência e ascensão social, diferenças se materializavam em resistências, rixas, brigas, homicídios, conforme nos relata Sidney Chalhoub (2012). Era preciso, então, uma transformação nas condutas do trabalhador, de uma educação das massas nas cidades:

Este primeiro movimento para transformar o agente social expropriado em trabalhador assalariado tem como alvo, então, a mente ou o espírito dos homens livres em questão. Desejava-se, na verdade, que os homens livres internalizassem a noção de que o trabalho era um bem, o valor supremo do pacto social. Note-se, ainda, que este movimento de controle dos espíritos e mentes lançava suas garras muito além da disciplinarização do tempo e do espaço estritamente do trabalho -isto é, da produção-, pois a definição do homem de bem, do homem trabalhador, passa também pelo seu enquadramento em padrões de conduta familiar e social compatíveis com sua situação de indivíduo integrado à sociedade, à nação. (CHALHOUB, 2012, p. 49).

Contudo, conduziremos esta interpretação no sentido de que não se almejava apenas reformar as mentes ou os espíritos, mas havia uma intenção de mudança que se materializava nos corpos, com a operacionalização de estratégias educacionais. Os discursos identificados com a modernidade deram importância e centralidade às estratégias pedagógicas que incidiam sobre o corpo, prescrevendo determinados comportamentos e práticas que aludiam a uma determinada educação física.

Muitas vezes atrelada a uma educação cívica no sentido de forjar uma identidade nacional, a educação física era tema que movia seus defensores na imprensa. Pois, a exemplo de uma educação mais utilitária, de uma escola voltada ao trabalho e preocupada com a formação de uma identidade nacional, a educação física, para seus defensores, era uma prática privilegiada em um cenário de reformas educacionais que ocorriam desde a década de 1920, e se efetivavam na década de 1930 (PAULILO, 2009). Nos jornais de grande circulação, como o Correio Paulistano, essas pedagogias não eram só defendidas, mas cobradas em relação aos governos. No artigo "Educação Cívica", aludia o jornal:

A educação physica, o ensino cívico e o de trabalhos manuais são obrigatórios em todas as escolas primarias, normaes e secundarias, não podendo nenhuma escola de qualquer desses graus ser autorizada ou reconhecida sem que satisfaça tal exigencia.

É o que dispõe o artigo 131, da Constituição de 10 de novembro.

A educação physica e os trabalhos manuais são de realização mais facil de a verdade é que muitas de nossas escolas, senão todas, já se acham, nesse particular, em perfeita consonancia com aquela exigência constitucional. Quanto á educação civica, entretanto, temos nossas duvidas. Em que consiste a educação civica?

É a que tem por fim desenvolver e solidificar o sentimento de pátria no espirito de todos os cidadãos. É a que se destina a despertar em nós uma consciencia propria, sem descuidar, não obstante, a formação de um nobre espirito de solidariedade humana. (EDUCAÇÃO CIVICA, Correio Paulistano, 8 set. 1938, p.5). 
Desse modo, essas pedagogias identificadas com uma escola moderna gozavam de prestígio nos jornais de grande circulação. Este era o caso da disseminação de uma educação física, a partir de agora identificada como "Educação Física", com letras maiúsculas, institucionalizada nas escolas e em cursos de formação civis. Cada vez mais pertinente, a escolarização das ginásticas, dos jogos e dos esportes era estimulada pelos veículos de imprensa. No caso específico de São Paulo, é possível perceber de forma nítida este prestígio quando o assunto era a organização de aparelhos estatais direcionados à "causa" da Educação Física. Ressalta o jornal Correio Paulistano, na reportagem "Em prol de uma raça mais forte":

Não é de hoje que os mestres da pedagogia vêm aconselhando, insistentemente, a educação physica ao par da educação intelectual.

Fundamentam, elles, sobejamente, as suas teorias, num combate efficaz áquelle velho preconceito que dominava a época do romantismo, segundo o qual a força muscular era incompatível com a atividade intelectual. Felizmente, a crença em apreço já passou para o rol das cousas mortas. Está por demais vulgarizada a pratica de exercícios physicos, cuja importancia é, actualmente, das mais relevantes, principalmente aos estabelecimentos de ensino.

A Escola "Caetano de Campos", que bem merece sua denominação de modelo, não podia descuidar-se desse elemento considerado essencial para a educação moderna: a gymnastica.

De facto: profissionais competentes obrigam os escolares daquelle estabelecimento fazer exercícios apropriados que os tornarão mais ágeis e resistentes. (EM PROL..., Correio Paulistano, 13 ago.1930, p. 5).

Para além da Escola Caetano de Campos, antiga Escola Normal de São Paulo, era preciso que as aulas de Educação Física fossem disseminadas a todo o sistema público estadual de ensino ao longo da década de 1930. Para isso, seria impreterível a formação de instrutores e professores na "Escola Superior de Educação Física", além da criação do Departamento de Educação Física, o que propiciou um incremento na oferta de profissionais especializados que puderam lecionar nas principais cidades do Estado de São Paulo. Contudo, antes de 1934, era preciso recorrer aos profissionais formados no Rio de Janeiro, especificamente, na turma de 1929 da Escola do Exército, que por iniciativa também de Fernando de Azevedo, então Diretor da Instrucção Publica do Districto Federal, foi reativada através de um convênio, formando uma turma de militares e civis. Particularmente, estas políticas públicas repercutiam positivamente na imprensa paulista. Para o Correio Paulistano, no texto "Educação Physica", Fernando de Azevedo visava:

[...] extender a todos os brasileiros, desde a primeira infancia, os benefícios da educação physica de accordo com princípios communs racionaes e scientificos já aplicados.

É necessária a obrigatoriedade dos exercícios physicos methodicos, desde a escola primaria. Para tanto, é preciso inicialmente interessar o professor primario, e isso, no Districto Federal, é objetivo já attingido, graças á boa vontade do prefeito Antonio Prado Junior e do director da Instrucção Publica, professor Fernando de Azevedo, empenhados nesse "desideratum" com o ardor de quem comprehende a sua importancia para o futuro da nacionalidade. Graças a eles, já uma turma de professores, em numero de 23, fez, em 1929, com grande dedicação e real proveito, um estagio de alguns mezes no Curso Provisorio da Escola de Sargentos, e se encontra hoje distribuída pelas escolas primarias do Districto Federal, com pleno conhecimento do methodo ali praticado. Outras turmas, naturalmente, succederão 
áquella e, dentro de poucos annos, estará adoptado o methodo necessário em todas as escolas da Republica. (EDUCAÇÃO PHYSICA, Correio Paulistano, 4 mai. 1930, p. 5).

Desse modo, a questão da Educação Física nas escolas era paulatinamente incentivada. Enfrentava, primeiramente, a necessidade de formação de professores civis. Neste contexto, quando Fernando de Azevedo assume a condição de Diretor do novo "Departamento de Educação de São Paulo", em fevereiro de 1933, ele convoca uma Comissão Estadual de Educação Física, evento noticiado pelo jornal Correio de São Paulo em sua primeira página, na reportagem intitulada "Instalou-se hontem a Comissão Estadual de Educação Physica":

Comunicam-nos do gabinete do director do Departamento de Educação:

"Na sede do Departamento de Educação, recentemente creado, reuniram-se ontem os quatro chefes do serviço das seções de educação fisica, srs. drs. Antonio Baíma, Americo R. Neto, Arne Enge e Fritjoff Detthow, sob a presidencia do dr. Fernando de Azevedo, diretor do Departamento.

Compareceu, tambem, o dr. Almeida Junior, chefe do serviço de Higiene e Educação Sanitaria Escolar, que se articula diretamente com as atividades da seção de educação física.

Tendo trocado idéas sobre as principais atividades de execução imediata, como a do preparo de professores de educação física, a construção de praças de ginastica para uso dos grupos escolares da capital e varias outras providencias. 0 dr. Fernando de Azevedo declarou instalada a Comissão Estadual de Educação Física, composta dos 4 chefes de serviço acima mencionados, sob a presidencia do dr. Antonio Baíma". (INSTALOU-SE HONTEM..., Correio de São Paulo, 10 fev.1933, p.1).

A despeito da saída repentina de Fernando de Azevedo da direção da educação pública em São Paulo, a comissão foi estruturada no "Departamento de Educação Physica" atrelado à Secretaria de Educação e da Saúde Pública de São Paulo, antigo Departamento de Educação, que tinha diversos objetivos, entre eles colocar em funcionamento a "Escola Superior de Educação Physica", criada por decreto em 1931, sem, contudo, funcionar até 1934, quando foi publicado seu regulamento e convocada a primeira turma no dia $1^{\circ}$ de agosto daquele ano. $\mathrm{Na}$ Revista de Educação foi transcrito o regulamento da escola. Em seus termos:

Art. 41. ${ }^{\circ}$ _ A Escola Superior de Educação Physica, creada pelo decreto $n^{\circ} 4.855$, de 27 de janeiro de 1931, constará de um curso para a formação de instructores de gymnastica serão as seguintes:

1aㅡ cadeira _ Anatomia humana

$2^{\text {a }}$ cadeira_Physiologia humana

$3^{\text {a }}$ cadeira _ Hygiene

4aㅡ cadeira _ Noções de psychologia educativa

5ª cadeira _ Educação Physica

6ª cadeira _ Noções de Orthopedia

7ª̣ cadeira _Historia da Educação Physica

Art. $43 .^{\circ}$ _ As matérias do curso para professores de educação physica serão as seguintes:

$1^{\text {a }}$ cadeira_Biologia 


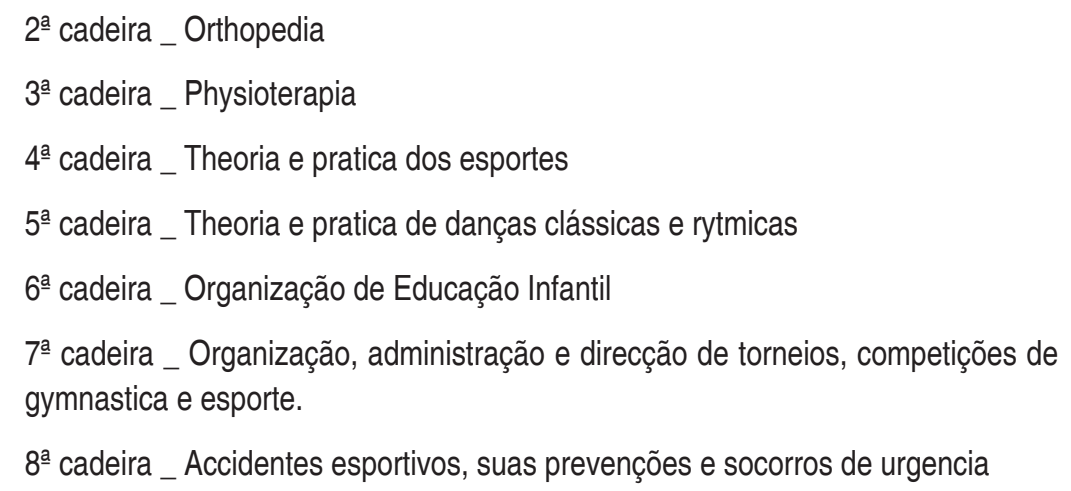

Art. 44. ${ }^{\circ}$ _ As cadeiras que constituem os cursos da Escola Superior de Educação Physica poderão ser divididas nas secções que a pratica aconselhar.

Art. 45. ${ }^{\circ}$ O curso para instructores de gymnastica e o de professores de educação physica serão de um anno cada um, constando de aulas theoricas e praticas.

$\S$ unico _Consideram -se aulas praticas as aulas de execução, coordenação, commando e fiscalização de exercícios e jogos.

\section{$[\ldots]$}

Art. $51 .{ }^{\circ}$ - Aos alumnos approvados em todas as materias do curso de professores de educação physica será concedido o diploma de Professor de Educação Physica, com as regalias e vantagens das leis.

Art.52. ${ }_{-}$É atribuição da Escola Superior de Educação Physica fornecer atestados de habilitação a instructores de gymnastica ou professores de educação physica. (FACTOS... 1934, p.209-210).

Ao observarmos os currículos para formação de instrutores e professores, percebemos uma tendência a um maior diálogo com as Ciências Biológicas. Das quinze cadeiras, sete tinham suas bases nestas ciências, duas ligadas às Ciências Humanas e da Educação e seis profissionalizantes. São as escolhas de conhecimentos, saberes e práticas tidas como eleitas em um currículo que podem demonstrar de qual educação física aqueles atores estavam falando. O nascedouro da "Escola Superior de Educação Physica" evidencia a racionalização das práticas corporais, pois elas eram compreendidas por sua sustentação, principalmente, na Medicina e nas Ciências Biológicas, que dialogavam brevemente com a Pedagogia e a História no sentido de legitimação de uma prática para além da experiência, que se diferencia do velho, do tradicional, que se aproxima da ciência e da tecnologia.

Tal investimento mereceu destaque da imprensa paulista. A Escola paulista era a segunda escola civil criada no país, posterior à Escola de Educação Física do Espírito Santo, criada em 1931, e anterior à Escola Nacional de Educação Física e Desportos, no Rio de Janeiro, de 1939. Assim noticiou o Correio Paulistano:

A sua inauguração, hoje

Terá lugar hoje, ás 10 horas, no play-ground do Parque D. Pedro II, a inauguração da Escola Superior de Educação Physica.

Nessa escola, que faz parte integrante do Departamento de Educação Physica do Estado, funccionará desde já o seu primeiro curso de instructores de gymnastica, cujos alumnos matriculados estão chamados para amanhã, ás 10 horas, no referido local. (GYMNASTICA , Correio Paulistano, 1 ago. 1934, p.7). 
No dia posterior, o evento ainda repercutia na reportagem "Inaugurou-se hontem a Escola Superior de Educação Physica":

Hontem, no "play-ground" do Parque D. Pedro II, realizou-se a inauguração da Escola Superior de Educação Physica. [...]

A nossa reportagem manteve com o dr. Americo R. Netto, secretario do Departamento, uma ligeira palestra. Em synthese, s. s. disse o seguinte:

- O Departamento de Educação Physica tem recebido innumeras inscripções. Dessas, cerca de $45 \%$ são mulheres. Quanto aos professores, estamos bem servidos: normalistas de ambos os sexos, tanto do Interior como da Capital, alguns academicos e varios monitores do exercito.

- Qual o programma do Departamento?

- O nosso programa está bem estudado. Em 1934, o curso será somente para instructores de gymnastica, sendo sua duração de oito mezes. Já em 1935, caso curso é acrescido com o de professores de educação physica, mais completo e desenvolvido. Nesse curso só serão matriculados os approvados no curso de instructores.

- E sobre o horário?

- As aulas praticas serão no período da manhã, das 7:30 horas em diante. Quanto aos locaes, escolhemos, para as moças, o Parque D. Pedro II, e, para os homens, o campo de esportes da Força Publica, no Canindé. As aulas theoricas, para ambos os sexos, serão dadas diariamente no Parque D. Pedro II, das 15 ás 16 horas, excepto aos sabados. Hoje serão ministradas as primeiras aulas.

- E quanto aos professores?

- Até agora, foram escolhidos os seguintes: dr. Arne Enge: physiologia, Hygiene e Educação Physica; dr. Francisco Pompeu do Amaral: Anatomia e Orthopedia; dr. Americo R. Netto: Psychologia educativa e Historia da educação physica.

(INAUGUROU-SE HONTEM..., Correio Paulistano, 2 ago. 1934, p.2).

A importância de Américo Netto não é trivial. Ao analisarmos sua rede de sociabilidades, observamos que ele, primeiramente, além de ser figura central na criação da Escola de Educação Física de São Paulo, também atuava na filial paulista da Associação Cristã de Moços, entidade de grande relevância na promoção de esportes norte-americanos e ingleses, na publicação da Revista Educação Physica (1932-1945), impressa pela filial carioca da Companhia Editora Nacional. Ou seja, era um agente histórico importante que se destacou na defesa de uma conciliação entre a ginástica e os esportes no currículo da Educação Física nas escolas (GOIS JUNIOR; MELO; SOARES, 2015).

Contudo, a Educação Física daquela escola superior era lembrada principalmente por seu apelo à ciência na análise das práticas ginásticas e esportivas. O relato do colunista Lellis Vieira sintetiza que lugar a Educação Física tinha no ideário dos paulistas nos anos de 1930. Completamente surpreso, Lellis Vieira tece uma série de elogios à Escola, enfatizando sua ciência e tecnologia, bem como seu papel no desenvolvimento da "raça":

Aquillo é positivamente um assombro. Não estamos exagerando. Temos a medida exacta das apreciações justas. E quem quiser certificar-se do adjectivo, que vá lá, visite 0 aparelhamento desse notavel instituto.

Nós mesmos pensavamos, como leigo nessas coisas, que educação physica fosse um problema simplista: um, dois, tres, um, dois, tres. Estende o braço, encolhe a perna, espicha o pescoço, funga o respiro... 
Pois senhores o negocio é serissimo, especialmente o capitulo medico. Installada admiravelmente num predio enorme, feito para Hospital, mas que se achava fechado, ali se vê um serviço completo de fichagem, a primeira biblioteca da America do Sul especializada no assumpto, salas de desenho, de controles, de estatística esta então, admiravel, e aparelhos de Raio X, cardiogrammas, aplicações elétricas, metabolismo basal, mesas operatorias, moveis cirúrgicos, fiscalização de toda a vida esportiva por meio de registros, assistencia accidental, finalmente, um conjunto que não se pode descrever em tres tirinhas de papel.[...]

A gente tem a impressão de que a Escola Superior de Educação Physica de São Paulo, é qualquer estabelecimento vulgar, commum, meia tigela, destinado apenasmente a endireitar cacundas camellórias e tornozelos...caôlhos! Vão lá ver o que é aquella obra. Grande concepção scientifica, ethnico-social, embasamento orgânico das populações que nos parques infantis já padronizadas para o Interior do Estado, serão amanhã o orgulho da raça.

Não é com gélea que se vence na vida. É com tutano muscular, de fibra, que se triunfa no duro... (VIEIRA, 1939, p. 3).

Não é um fato isolado a escolha do título do artigo jornalístico de Lellis Vieira "Pela Raça!", muitas vezes relacionada ao discurso de "fortalecimento da raça", a Educação Física era percebida como instrumento de regeneração do povo, daí a necessidade de sua escolarização e presença em parques infantis. Corroborando a análise de Chalhoub (2012), que evidencia discursos interessados na transformação dos espíritos dos trabalhadores brasileiros, a imprensa aludia à formação de corpos racionalizados, disciplinados, marcados pela representação de uma raça forte e saudável. Nessa construção, determinadas práticas corporais, como a ginástica, eram enaltecidas como modernas e outras tradicionais, como a capoeira, eram silenciadas.

Figura 1 - Aula de Ginástica

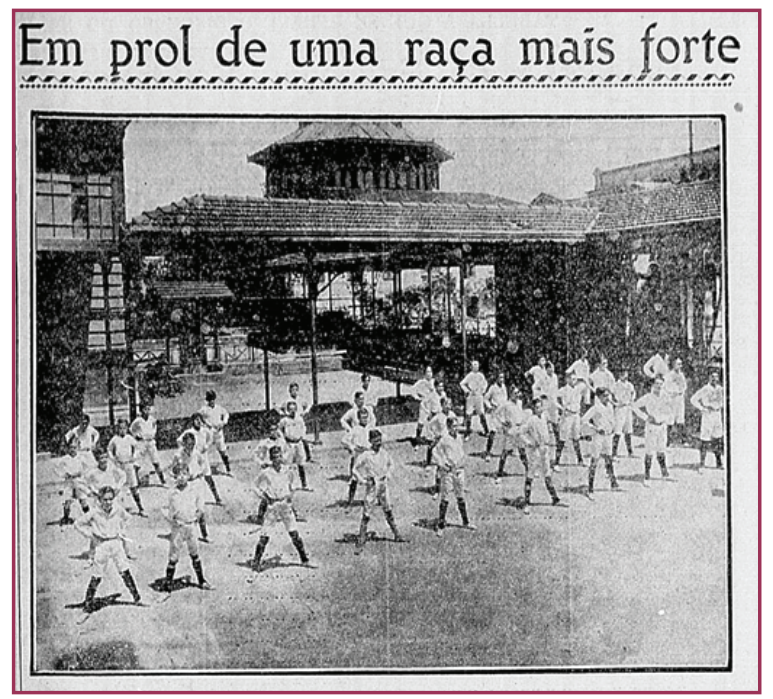

Fonte: Correio Paulistano, São Paulo, p. 5, 13 ago. 1930. Arquivo Público do Estado de São Paulo.

Ao imaginarmos uma identidade brasileira, dificilmente a prática de ginástica seria marcante como representação das escolhas sobre o que chamamos atualmente de cultura brasileira. Diferentemente, na década de 1930, havia uma imagem sobre o "novo" brasileiro, transformado pela educação e saúde, que, é necessário frisar, possivelmente estava muito mais 
presente entre os intelectuais, a imprensa e os seus leitores do que nas representações sobre o país a partir de sua população rural ou mais pobre. Contudo, a imprensa dava visibilidade ao ideário moderno, investindo sobre a juventude no campo educacional, que incluía, sem dúvida, a disciplina corporal e a Educação Física. Jacques Le Goff (2013) explica-nos que o termo "moderno" assinala a tomada de consciência de uma dada sociedade em relação a uma ruptura com o passado. Ressalta, ainda, que os países atingidos pelo colonialismo europeu precisaram enfrentar a questão do atraso no século XX. Assim, o anúncio do moderno estava paralelo à afirmação da identidade nacional. Em um processo de identificação, com negação e oposição entre antigo e moderno, a "modernização" teve certas características que, para Le Goff (2013), separam uma "modernização equilibrada", em que o êxito da penetração do moderno não destruiu o antigo, como, por exemplo, no Japão, de uma "modernização por tentativas" que procurou conciliar antigo e moderno não de forma equilibrada, mas parcial, como no caso brasileiro. Essa interpretação leva-nos a compreender que os jornais paulistas silenciavam sobre as tensões entre as pedagogias modernas voltadas ao corpo e outras práticas presentes no cotidiano das cidades brasileiras, como, por exemplo, a capoeira ou as práticas circenses, que naquele momento eram excluídas do currículo superior de uma Educação Física marcadamente influenciada por perspectivas norte-americanas e europeias (SCHNEIDER et al., 2016; SOARES, 2004). Em outras palavras, quando se observa a opinião jornalística a partir de seus cronistas, há tentativas de evidenciar práticas identificadas com o científico, o organizado, o planificado, o racionalizado, como a ginástica, mas também com os esportes e jogos em uma pedagogia moderna, enfim, em uma Educação Física que dava centralidade a determinadas práticas. A "Escola Superior de Educação Physica" era central neste projeto educacional. Em 1939, comemora o Correio Paulistano, na reportagem "Escola Superior de Educação Physica":

\footnotetext{
[...] realizou-se hontem nos salões de exposição do Parque da Agua Branca, a abertura dos cursos da Escola Superior de Educação Physica.

É opportuno recordar que esse notavel instituto de ensino physicultor, teve neste ultimo anno um desenvolvimento que ultrapassou a todas as espectativas, após longo tempo de marasmo e abandono. Só na matricula de 1939, verifica-se 0 ingresso de 306 alumnos e alumnas, constituindo esse facto, o melhor documento comprobatorio da efficiencia, do brilho, do surto ascencional e do enthusiasmo reinante em nosso meio, pela cultura physica. (ESCOLA SUPERIOR..., Correio Paulistano, 2 abr. 1939, p.5).
}

Tanto os esportes como as ginásticas passam a ser percebidos como práticas corporais capazes de desenvolver a saúde da juventude, já que podem ser entendidas como hábito higiênico. Garantidas as questões objetivas para seu oferecimento nas escolas, como a formação de professores, era necessário demonstrar os resultados de sua implantação na década de 1930. Na tentativa de aproximar-se deste cotidiano nas escolas, deparamonos com as festividades e comemorações organizadas pelos estabelecimentos de ensino, que objetivavam levar à comunidade externa suas escolhas sobre o trabalho pedagógico desenvolvido. É neste âmbito que uma racionalização dos corpos ganha destaque, por isso o protagonismo da "Escola Superior de Educação Physica" no noticiário do Correio Paulistano, quando o tema era educação da juventude: 
Realizaram-se depois interessantes demonstrações de exercicios physicos por alumnos da Escola Superior de Educação Physica e dos grupos escolares.

A primeira demonstração nesse sentido constituiu em vários números de gymnastica rythmica, executados por um grupo de alumnas de grande belleza plastica. A seguir, foram executadas varias pyramides por alumnos da Escola Superior de Educação Physica, do grupo escolar "Miss Browne", e por escoteiros da Associação Escolar, demonstrações essas que despertaram tambem grande interesse.

A festa, promovida pelo Departamento de Educação obteve grande exito, sendo abrilhantada pelas bandas de musica da Força Publica e da Guarda Civil. (DEZ MIL..., Correio Paulistano, 13 out.1938, p. 6).

Figura 2 - Ginástica nas Festividades

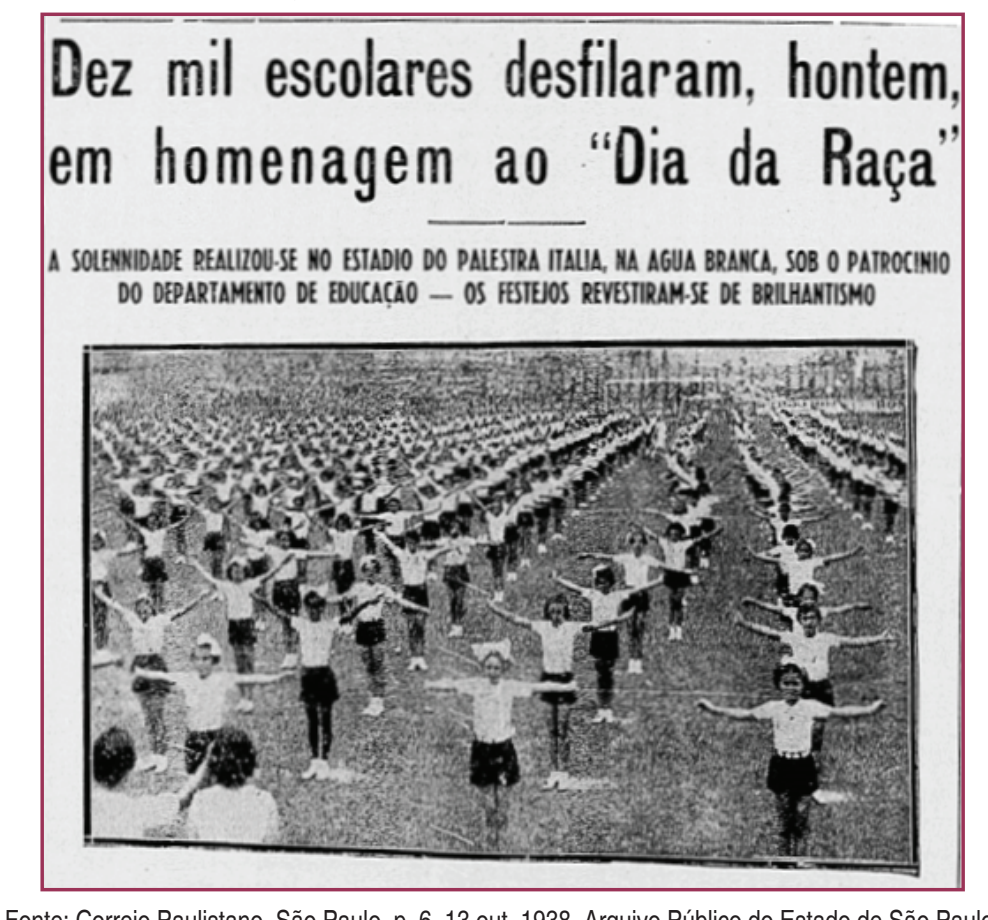

Fonte: Correio Paulistano, São Paulo, p. 6, 13 out. 1938. Arquivo Público do Estado de São Paulo.

Todo este investimento na Educação Física não foi administrado de forma homogênea nas escolas. Era preciso lidar também com resistências por parte dos pais, enfim, era necessária uma mudança no campo cultural em relação às práticas corporais, o que não poderia ser alcançado no curto prazo. Neste sentido, era impreterível o discurso dos jornais, mas também de educadores que se enfileiraram na defesa da Educação Física. Nas palavras do Prof. Raymundo Pastor:

A maioria dos paes têm uma concepção errônea para não dizer pejorativa das matérias chamadas do segundo grupo. Para elles o bom professor não perde tempo ensinando essas matérias, que julgam mais do que inuteis, perniciosas, por absorverem tempo que poderia ser destinado ao ensino de coisas mais necessarias á vida pratica.

Escapa, como vemos, aos responsáveis pela educação das crianças, a razão profunda que determinou a inclusão dessas disciplinas nos programmas escolares. De facto, as modificações psyco-physicas ou sensório-motrizes por ellas determinadas no organismo, não são de natureza a serem percebidas á primeira vista; não sendo por isso de estranhar que sejam consideradas um luxo desnecessario. 
Se os paes repugnam o ensino de matérias julgadas ineficazes á vida pratica que espera a maioria das crianças, embora reconheçam, no intimo, que se trata de conhecimentos utilizaveis, que dizer, porem, em relação ao jogo infantil, para justifical-o na escola, aos olhos estarrecidos dos paes, que não se cançam de repetir que mandam os filhos á escola para aprender e não para brincar?

Á gymnastica póde-se atribuir papel importante na conservação da saude, na acção orthopedica (PASTOR, 1934, p.3).

Sem dúvida, os argumentos atrelados à saúde eram os mais penetrantes no que diz respeito à justificação de uma Educação Física nas escolas. Se brincar era inútil, os jogos a partir de uma lógica científica promoviam o desenvolvimento infantil, garantindo-lhe uma infância e juventude preparadas para o mundo do trabalho, por isso utilitária. Mas também porque aquelas práticas conformavam nos corpos uma moralidade ao mesmo tempo da eficiência com os esportes e da ortopedia com as ginásticas.

\section{CONSIDERAÇÕES FINAIS}

As representações que orbitavam a institucionalização da Educação Física em São Paulo, na década de 1930, residiam na conquista de corpos fortes e saudáveis forjados na juventude e na infância. Os discursos jornalísticos, sobretudo a partir de conhecimentos científicos em voga, pareciam pautar a formação superior ao lado de práticas modernas, como esportes, jogos e ginásticas. Equipamentos e tecnologias criavam a atmosfera propícia para 0 espanto dos leigos em relação à organização de uma escola superior especializada em Educação Física. Tratava-se não apenas de uma prática, mas de um conhecimento racionalizado a partir de aparatos maquínicos, como aparelhos de Raio X, cardiogramas e aplicações elétricas. Além disso, o protagonismo da Escola Superior nas demonstrações públicas e festividades cívicas do Departamento de Educação evidenciava também as tentativas de aproximação de seus preceitos educacionais junto às escolas primárias e secundárias. Particularmente, a imprensa foi uma relevante aliada na publicidade de seus serviços, afinal era uma Educação Física pautada nos valores da modernidade.

Contudo, ensina-nos Jacques Le Goff (2013) que a afirmação da modernidade referese, sobretudo, a um meio restrito formado por intelectuais e tecnocratas. Como uma consciência do progresso, a modernidade é um plano em elaboração, que sempre é identificado como conquista de um grupo, de uma elite, de círculos restritos, mesmo quando suas práticas alcançam populações mais amplas. No caso da Educação Física, mesmo diante do apoio irrestrito da imprensa, com sua crescente institucionalização, a necessidade de legitimação de suas práticas a partir de discursos pedagógicos ainda era patente, indicando que as práticas corporais identificadas com o discurso científico não estavam completamente inseridas no cotidiano dos paulistanos. Ainda era preciso naquele momento defendê-las, pois elas estavam em um caminho de institucionalização. Neste sentido, esta Educação Física paulista do ensino superior era um projeto intelectual restrito a um grupo muito próximo dos discursos e práticas educacionais oriundos da Europa e dos Estados Unidos. Em uma "modernização em tentativas" (Le GOFF, 2013), em uma cidade como São Paulo, outras práticas corporais existentes no campo cultural eram silenciadas nestes projetos pedagógicos. 


\section{REFERÊNCIAS}

AZEVEDO, Fernando. O problema da regeneração. Revista Educação Physica, (Rio de Janeiro), n. 5, p. 14,1933.

CAMPOS, Raquel Discini. No rastro dos velhos jornais: considerações sobre a utilização da imprensa não pedagógica como fonte para a escrita da história da educação. Revista brasileira da história da educação, v. 12, n. 1, p. 45-70, 2012.

CHALHOUB, Sidney. Trabalho, lar e botequim: o cotidiano dos trabalhadores no Rio de Janeiro da belle époque. 3. ed. Campinas: Editora Unicamp, 2012.

DEZ MIL... escolares desfilaram, hontem, em homenagem ao "Dia da Raça". Correio Paulistano, São Paulo, p. 6, 13 out. 1938.

DIRECTORIA DO ENSINO, A educação physica nas escolas. Correio Paulistano, São Paulo, p. 24, 13 mar. 1938.

EDUCAÇÃO CIVICA. Correio Paulistano, São Paulo, p. 5, 8 set. 1938.

EDUCAÇÃO PHYSICA. Correio Paulistano, São Paulo, p. 5, 4 maio 1930.

EM PROL... de uma raça mais forte. Correio Paulistano, São Paulo, p. 5, 13 ago. 1930.

ESCOLA SUPERIOR... de Educação Physica. Correio Paulistano, São Paulo, p. 5, 2 abr. 1939.

FACTOS e iniciativas: da Escola Superior de Educação Physica. Revista de Educação, (São Paulo) v. 7, p. 209-210, set. 1934.

GOIS JUNIOR, Edivaldo; MELO, Victor Andrade de; SOARES, Antônio Jorge Gonçalves. Para a construção da nação: debates brasileiros sobre educação do corpo na década de 1930. Educação e Sociedade, v. 36, n. 131, p. 343-360, 2015.

GYMNASTICA: Escola Superior de Educação Physica. Correio Paulistano, São Paulo, p. 7, 1․ ago.1934.

INAUGUROU-SE HONTEM... a Escola Superior de Educação Physica. Correio Paulistano, São Paulo, p. 2, 2 ago.1934.

INSTALOU-SE HONTEM... a Comissão Estadual de Educação Physica, Correio de São Paulo, p. 1, 10 fev. 1933.

KRÜGER, Michael. Body Culture and Nation Building: The History of Gymnastics in Germany in the Period of its Foundation as a Nation-State. International Journal of the History of Sport, v. 13, n. 3 , p. $409-417,1996$.

LE GOFF, Jacques. História e memória. Campinas: EdUnicamp, 2013.

LUNDVALL, Suzanne. From Ling Gymnastics to Sport Science: The Swedish School of Sport and Health Sciences, GIH, from 1813 to 2013. International Journal of the History of Sport, v. 32, n. 6, p. 789-799, 2015.

MACRAE, Eilidh H.R. Exercise and education: facilities for the young female body in Scotland, 19301960. History of Education, v. 41, n. 6, p. 749-769, 2012. 
OKAY, Cüneyd. Sport and Nation Building: Gymnastics and Sport in the Ottoman State and the Committee of Union and Progress, 1908-18. International Journal of the History of Sport, v. 20, n.1, p. 152-156, 2003.

PASTOR, Raymundo. O Jogo: ojeriza dos paes pelo jogo. Revista de Educação (São Paulo), v. 8, n.8, p.3, dez. 1934.

PAULILO, André Luiz. As estratégias de administração das políticas públicas de educação na cidade do Rio de Janeiro entre 1922 e 1935. Revista Brasileira de Educação, v. 14, n. 42, p. 440-455, 2009.

SCHARAGRODSKY, Pablo. El discurso médico y su relación con la invención del oficio de 'educador físico': entre la heteronomia solapada y la autonomía vigilada (Argentina, 1901-1931), In: SCHARAGRODSKY, P. Miradas médicas sobre la cultura física en Argentina (1880-1970). Buenos Aires: Prometeo, 2014. p.101-148.

SCHNEIDER, Omar.; FERREIRA NETO, Amarílo; SILVA MELLO, André; SANTOS, Wagner; VOTRE, Sebastião Josué; ASSUNÇÃO, Wallace Rocha. American influences in Brazilian physical education: clues in the specialised periodical press (1932-1950). Sport, Education and Society, v. 21, n. 7, p. 1053-1070, 2016.

SENNETT, Richard. Carne e Pedra: o corpo e a cidade na civilização ocidental. Rio de Janeiro: Record, 1997.

SEVCENKO, Nicolau. O prelúdio republicano, astúcias da ordem e ilusões do progresso. In: SEVCENKO, N.(org). História da vida privada no Brasil. São Paulo: Companhia das Letras, 1998, v. 3, p. 7-48.

SEVCENKO, Nicolau. Orfeu Extático na Metrópole: São Paulo nos frementes anos 20. 4. ed. São Paulo: Companhia das Letras, 1992.

SILVA, Ana Márcia. Entre o corpo e as práticas corporais. Arquivos em movimento, v.10, n.1, p.520, 2014.

SKIDMORE, Thomas. Preto no Branco. Raça e Nacionalidade no pensamento brasileiro. São Paulo: Paz e Terra, 1989.

SOARES, Carmen Lucia. Educação física, raízes européias e Brasil. 3. ed. Campinas: Autores Associados, 2004.

THALASSA, Ângela. Correio Paulistano: o primeiro diário de São Paulo e a cobertura da Semana de Arte Moderna. 2007. 158 f. Dissertação (Mestrado) - Programa de Pós-graduação em Comunicação Social, PUC, São Paulo, 2007.

VIEIRA, Lellis. Pela Raça! Correio Paulistano, São Paulo, p. 3, 16 ago.1939.

VIGARELLO, Georges. A invenção da ginástica no século XIX: movimentos novos, corpos novos.

Revista Brasileira de Ciências do Esporte, v. 25, n. 1, p. 9-20, 2003.

WELSHMAN, John. Physical culture and sport in schools in England and Wales, 1900-40.

International Journal of the History of Sport, v. 15, n. 1, p. 54-75, 1998.

Apoio:

FAPESP, Projeto Regular, Processo n. 2016/00167-6.

A ortografia da época foi mantida nas citações dos documentos. 